\title{
Through service providers' eyes: health systems factors affecting implementation of tuberculosis control in Enugu State, South-eastern Nigeria
}

Daniel Chukwuemeka Ogbuabor ( $\sim$ ogbuabordc@gmail.com )

University of Nigeria Enugu Campus

Research article

Keywords: Tuberculosis, Control programme, Health systems, Constraints, Service providers, Nigeria

Posted Date: December 9th, 2019

DOl: https://doi.org/10.21203/rs.2.18500/v1

License: (1) (1) This work is licensed under a Creative Commons Attribution 4.0 International License.

Read Full License

Version of Record: A version of this preprint was published at BMC Infectious Diseases on March 6th, 2020. See the published version at https://doi.org/10.1186/s12879-020-4944-9. 


\section{Abstract}

Background Well-functioning health systems are essential to achieving global and national tuberculosis (TB) control targets. This study examined health system factors affecting implementation of TB control programme from the perspectives of service providers.

Methods The study was conducted in Enugu State, South-eastern Nigeria using qualitative, crosssectional design involving 23 TB service providers (13 district TB supervisors and 10 facility TB focal persons). Data were collected through in-depth, semi-structured interviews using a health system dynamic framework and analysed thematically.

Results Stewardship from National TB Control Programme (NTP) improved governance of TB control, but stewardship from local government was weak. Government spending on TB control was inadequate, whereas donors fund TB control. Poor human resources management practices hindered TB service delivery. TB service providers have poor capacity for data management because changes in recording and reporting tools were not matched with training of service providers. Drugs and other supplies to TB treatment centres were interrupted despite the use of a logistics agency. Poor integration of TB into general health services, weak laboratory capacity, withdrawal of subsidies to community volunteers and patent medicine vendors, poorly funded patient tracking systems, and ineffectual TB/HIV collaboration resulted in weak organisation of TB service delivery.

Conclusion Health systems strengthening for TB control service must focus on effective oversight from NTP and local health system; predictable domestic resource mobilisation through budgets and social health insurance; training and incentives to attract and retain TB service providers; effective supply and TB drug management; and improvements in organization of service delivery.

\section{Introduction}

Well-functioning health systems are essential to achieving global and national tuberculosis (TB) control targets [1]. The End TB Strategy identified integrated, patient-centred care, bold policies and supportive systems as pillars to end TB by 2030 [2]. Comprehensive changes to policies and regulation, organisational structures, processes and relationships and effective use of resources are needed to achieve and sustain goals of TB control programme $[3,4]$. Nonetheless, low- and middle-income countries (LMICs) still struggle with health system strengthening for TB control.

Health systems factors that strengthened TB control include effective national strategies [5-7]; strong stewardship from district government [8]; donor funding [5, 8-13]; inclusion of TB in social health insurance schemes [14, 15]; earmarked funding for TB [16]; medical vouchers and subsidies [17, 18]; providers' satisfaction with directly observed treatment short course [19]; incentives to programme staff [20]; patient-centred approaches and intersectoral collaboration [6, 16, 19]; motivated and dedicated healthcare workers [16, 19]; effective supply and drug management system [8, 21]; use of dedicated 
logistics agency to distribute TB drugs [9, 22]; and electronic reminders to improve treatment adherence [17].

Constraints to TB control include perception that TB control is less important than other public health programs [20, 23]; weak accountability relationship between provincial/regional and district TB programme management [7, 12, 24]; insufficient community involvement [25]; and low public spending on TB [5-7, 9-13]. TB control have been limited by lack of skilled staff $[4,10,11,19,22]$; lack of incentives for service providers [4, 5, 10]; lack of utilization of various levels of health staff and health facilities [25]; poor attitude and weak commitment of health workers towards deployment to TB services [22, 23], inadequate training $[10,11,19]$, and lack of laboratory staff $[5,22,23]$. Poor TB data management capacity [22]; frequent revisions of reporting formats [5]; and ineffective electronic recording and reporting system [14]. Shortages of TB drug [7, 22] and unavailability of laboratory supplies and equipment hinder TB service delivery $[7,11,22]$. Poor adherence to GeneXpert algorithm, interrupted supply of cartridges, lack of replacement of damaged modules, poor maintenance, and poor recording and reporting limit usefulness of GeneXpert in TB diagnosis [14,26, 27]. Poor adherence to national guidelines [11, 22, 23]; dilapidated infrastructure $[5,12,23]$ weak TB/HIV integration $[10,12,14,24,28]$; lack of public-private mix $[10,12,23]$ and poor integration into general health services hinder effective TB service delivery $[5,29,30]$.

Nigeria's national strategic plans for TB control emphasised health system strengthening (31). However, after over two decades of TB control, Nigeria has about $76 \%$ funding gap and $24 \%$ of TB cases notification, and is one of three countries accounting for $80 \%$ gap in TB notification [1]. Yet, studies using systems thinking to analyse implementation of TB control in Nigeria are scarce. The study therefore examined health system factors affecting implementation of TB control programme in Enugu State, Nigeria from the perspectives of district-level service providers. Such evidence would inform policy changes to ensure universal access to TB services in low resource, high TB burden settings.

\section{Methods}

\section{Conceptual framework}

The study was guided by health systems framework by Van Olmen and colleagues [32]. The framework builds on World Health Organization's six building blocks of a health system [33] and uses input, process, outcomes and goals to explain health systems dynamics (Figure 1). The goals of TB control are reductions in TB mortality and incidence. Universal coverage, treatment success and responsiveness are outcomes of optimal TB control programme. TB diagnosis and treatment is considered service delivery block and equals the process in the framework. Health financing, human resources, medical technology and health management information system (HMIS) serve as inputs into service delivery. Governance, which entails policy guidance, policy coordination, regulation of different functions, optimal allocation of resources and accountability, influences both the input and process. This framework was chosen because it explains how interactions of governance, inputs and process would lead to improved implementation of TB control and better health outcomes. 


\section{[INSERT FIGURE 1 HERE]}

\section{Study Setting}

The study was conducted in Enugu State, South-east Nigeria. The National TB Control Programme (NTP) is headed by a state control officer. Each local government area (LGA) has a TB supervisor (LGTBS). The state has 71 and 41 TB treatment centres in public and private health facilities respectively. Each treatment centre has a TB focal person.

\section{Research design}

The study adopted a cross-sectional, qualitative study design using in-depth, semi-structured interviews.

\section{Study population and sampling strategy}

Study subjects were LGTBS and facility TB focal persons in Enugu state. All 17 LGTBS were included in the study. However, data from LGTBSs was saturated after the thirteenth interview [34]. To select facility TB focal persons, the 17 LGAs were categorized into low (8 LGAs) and high (9 LGAs) case finding districts based on case notification, an important indicator of successful TB control programme [1, 31]. From each category, 5 LGAs were purposively selected. One TB treatment centre was purposively selected from each LGA. The TB focal persons in the selected treatment centres were interviewed. Maximum variation sampling was used to ensure that both rural and urban LGAs and all levels of facilities were represented (Table 1).

\section{[INSERT TABLE 1 HERE]}

\section{Data collection}

Twenty-three participants were interviewed between January and April 2017 using pre-tested, semistructured in-depth interview guide (Appendix 1). The interview questions were informed by the conceptual framework, adapted to TB control programme. Participants were identified using health officials as gatekeepers. Interviews were held in offices or health facilities, conducted in English and lasted about 60 minutes. All interviews were audiotaped, transcribed verbatim and verified by participants for accuracy of transcription. 


\section{Data analysis}

Data were analysed using a framework approach. Deductive and inductive strategies were used to code the transcripts in NVivo 11 software. Main themes were deduced from health systems' building blocks. Inductive codes were generated by familiarization with data and assigning codes to emerging themes. Coding was carried out by two persons and inconsistencies resolved by consensus. The LGTBS validated the study findings during a programme review meeting, which improved the validity of the findings.

\section{Ethical consideration}

The study was approved by Health Research Ethics Committee of Enugu State University Teaching Hospital, Parklane, Enugu, Nigeria. Written, informed consent was obtained from all participants.

\section{Results}

Findings are presented thematically using health system building blocks deduced from the study's conceptual framework (Table 2).

\section{[INSERT TABLE 2 HERE]}

\section{Leadership and governance}

Stewardship from the State and Local Governments emerged as key theme. All LGTBS received regular managerial oversight from the state TB programme. Similarly, most facility TB focal persons stated that "TB supervisors are always available when we need their advice, or we have questions or clarifications" (FP5). Quarterly review meetings offered opportunity for joint programme planning and coordination and holding LGTBS accountable. LGTBS serve under Primary Health Care Coordinators (PHCCs), who manage LG's health system. Nonetheless, most PHCCs, except those who were LGTBS prior to their appointment as PHCC, were unsupportive of TB control. It was explained that "because money does not come from the state ..., TB control program is not important" (TBS3) to local government officials. Furthermore, facility TB focal persons noted that PHCC rarely visited health facilities.

\section{Financing of TB control program}


Most participants stated that NTP has been donor-driven while public spending on TB control is low. As one supervisor stated, "TB programme is donor-driven. If I should say my mind, the government is not doing what it should" (TBS1). At the state level, allocated funds are not released to TB programme. At LG level, unlike other public health programs, TB control programme does not have a budget. Government officials feel that "we are collecting dollars from these development partners; why come to look for naira" (TBS1); and "we don't have anything (incentive) coming out of the program" (TBS10). Although LGs agreed to replace TB supervisors' motorcycles, no LG ever supplied motorcycle to LGTBS, which limits supervision, community mobilization, and contact and defaulter tracing. One facility TB focal persons lamented "I have written the local government chairman severally through the head of department of health, for financial support to build TB laboratory. They both signed, but till now, I have not seen anything from them" (FP3).

\section{Human resources for health}

Inadequate staffing, posting and transfer, supervision, remuneration and training emerged as key themes. Inadequate staffing stemmed from unwillingness of health workers to work in NTP due to stigma and lack of incentives. Consequently, TB service providers reported high workload: "my workload is high. It is not only TB services that I provide. I am also the anti-retroviral therapy focal person" (FP7). Most participants observed that trained TB service providers are frequently transferred out TB treatment centres. Few participants noted the social restriction to the posting or transfer of female health workers. Most participants agreed that supervision was supportive: "if there are things we are doing wrong, they correct us, ... and if there are things we are doing very well, they still commend us" (FP5). However, supervision is limited by "lack of functional motorbike and allowances to cover fuel and maintenance" (TBS5). Most LGAs were owing staff several months' salaries. Yet, financial incentives are scare especially among facility TB focal persons who "do not get any incentive" (TBS3). Most participants noted that there are many untrained TB focal persons. External training was preferred to on-the-job training because "they do not give us anything, except when we go for seminar" (FP4).

\section{Health information system}

Most participants indicated that recording and reporting tools were available but frequently changed without prior training of service providers. One participant stated: "they used to change the pattern and the format, which we find very difficult to cope with" (FP3). Modifications in tools were adaption to changes in TB control strategies: "we changed from eight months to six months treatment. Now we are addressing HIV, drug resistant TB and presumptive cases" (TBS5). Poor recording and reporting also resulted from work overload and lack of incentives. Electronic Tuberculosis manager (ETBM) has been 
rolled out to high burden facilities and LGTBS. Most participants perceived that ETBM would enable timely and complete recording and reporting. Few participants anticipated that ETBM would add to workload of service providers.

\section{Medical / Drug Supplies}

Most participants stated that TB drug supplies were interrupted during the preceding year: "a quarter would pass without supply" (FP6). Although, a logistics organization was contracted by the NTP to supply drugs directly to TB treatment centres, "they cut corners by dropping all the supplies meant for facilities in an LGA at one facility and expect individual facilities to come and pick their supplies there." (TBS1). Most TB treatment centres coped by borrowing drugs from other health facilities. Few participants explained extrapulmonary TB patients and TB patients weighing above $70 \mathrm{~kg}$ required more than one drug kit to meet their dosage requirements. A facility TB focal person remarked that "we have to de-kit in order to make it up for six months"(FP6). Human immunodeficiency virus (HIV) test kits were no longer supplied to TB treatment centres. A LGTBS asserted: "for the past 2 years, we have not received any HIV test kits" (TBLS3). Consequently, some health workers procure HIV test kits and charge fees for HIV screening.

\section{Service Delivery}

Most providers stated that TB is poorly integrated into general health services due to stigma by health workers, concern for contracting TB and lack of financial incentives. As explained, "some health workers refuse participating in TB control because of fear that they might contract TB" (TBS5); or "that nothing is coming out of it (TB programme), unlike malaria, monitoring and evaluation, and immunization" (TBS9). Most providers reported availability of functional microscopic centres. However, some providers indicated that TB diagnosis is constrained by lack of space, damaged microscope and lack of laboratory staff: "I have up to 10, but only 1 is functional" (TBLS2). Lack of dispatch riders, breakdown of machine, varying days of operations, and absence of support for sputum transport constrained use of GeneXpert for TB diagnosis. Withdrawal of incentives constrained involvement of community volunteers and patent medicine vendors. As one participant stated, "Usually, community volunteers received monthly stipends, but since GHAIN (a development partner) stopped it and government could not sustain it, all of them declined" (FP1). Also, "only very few of patent medicine vendors, who are health workers, still refer suspects to TB programme" (TBLS6). Some providers revealed that patient tracking systems is weak due to poor funding for contact and defaulter tracing, while TB/HIV collaboration was limited to comprehensive sites.

\section{Discussion}


Whereas stewardship from the NTP improved district TB service delivery, stewardship from local government (LG) was weak despite existence of memorandum of understanding between LGs and NTP. Effective bureaucratic relationship between state and LG TB programmes in this study contradicts evidence of poor stewardship in India, Ghana and South Africa [7, 12, 24]. In our setting, accountability relationship was enhanced by programme management support, supportive supervision and quarterly performance review meetings. Nevertheless, the weak stewardship from the LG confirms previous evidence that TB control program is perceived as less important than other public health programmes [20, 23], but contrasts evidence of strong political commitment from district governments in Pakistan [8]. Unmet expectation of local officials of financial incentives from NTP and perception that partners support TB control explained low responsiveness of LGs. Since governance affects input and process of TB control, LG officials need to strengthen stewardship of and become more responsive to TB control program.

This study also found that government spending on TB control was inadequate, which is similar to evidence from several studies where donors, instead of governments, drive TB control efforts [5-13]. In this study, non-release of budgeted funds at the state-level and complete absence of TB in LG budgets resulted in persisting TB funding gap and unlikelihood of sustainability of TB control. As external funding declines, all tiers of government in Nigeria need to improve financing of TB control through budgets. Also, Nigeria's efforts to decentralise social health insurance to states presents an opportunity to include TB in social health insurance schemes $[14,15]$, given that Nigerian TB patients incur catastrophic costs $[35,36]$. Moreover, it might be helpful to consider medical vouchers and subsidies for poor TB patients $[17,18]$.

This study's findings revealed that poor human resources management practices and inadequate training of TB service providers hindered TB control. These findings are consistent with lack of skilled staff $[4,10$, 11, 22]; lack of incentives for TB service providers [5, 10]; inadequate training [10, 11, 19]; and poor attitude and weak commitment of health workers towards deployment to TB services [22, 23]. In contrast, evidence from European countries show that skilled and motivated healthcare workers enabled TB control [16]. Strategies that aim at improving TB control workforce must address shortages of staff, stigma by health workers and lack of incentives to TB service providers. Additionally, broad contextual factors underlying human resource crisis especially social restriction to deployment of female health workers and delayed payment of staff salaries warrant attention of decision makers.

The findings revealed that TB service providers have poor capacity for recording and reporting TB data due to mismatch between changes in tools and training of service providers, which is similar to evidence from Ethiopia and Nigeria [5, 22]. Even though, changes in tools were adaptation to new developments in TB control program, lack of training meant that TB service providers did not completely fill tools and required constant supportive supervision. A strategy to improve data management was introduction of electronic recording and reporting system. However, experiences from South Africa suggest that operational challenges limited effectiveness of electronic recording and reporting system [14]. Nigeria's NTP would need to improve on-the-job capacity building of service providers on data management, while addressing the limitations of electronic recording and reporting system. 
The findings of this study that drugs and other supplies to TB treatment centres were interrupted are consistent with evidence of shortages of TB drug and laboratory supplies elsewhere [7, 11, 22], but contrast evidence of effective supply and drug management in Pakistan [8]. Although use of dedicated logistics agency to distribute TB drugs improved TB drug supply system [9, 22], experiences in our study area reveal that TB drugs for an entire district were often dumped in one health facility. Equally, absence of drug kits tailored to extrapulmonary TB patients and TB patients weighing $70 \mathrm{~kg}$ and above. Hence, service providers must augment one drug kit to meet their dosage requirements, which depletes the stock. Sustainable TB drug supply system would entail strengthening the logistics agency and improving the capacity of NTP to forecast TB drug needs.

Weak TB service delivery system was found as a key constraint to TB control. Consistent with findings of previous studies $[5,29,30]$, integration of TB into general health services was weak. Social stigma and concern for contracting TB meant that health workers refuse deployment to and participation in TB control programmes. Also, the findings of weak laboratory capacity due to lack of space, damaged microscopes, attrition of laboratory staff and operational challenges of GeneXpert, are like evidence from previous studies $[5,11,14,22,23,26,27]$. Equally, poor involvement of community volunteers and patent medicine vendors due to withdrawal of financial incentives hindered TB service delivery. Although TB service providers have used electronic reminders to improve treatment adherence similar to China's experience [17], weak patient tracking systems resulted from poor funding and lack of transportation. Notwithstanding existence of guidelines for TB/HIV integration, weak TB/HIV collaboration is similar to evidence from other studies $[10,12,14,24,28]$. Policies to improve TB service delivery system must address stigma among health workers, strengthen laboratory capacity, incentives to community volunteers and patent medicines vendors, improve funding of patient tracking and bolster TB/HIV integration.

This study adds to the growing scholarship using health systems lens to examine disease control programmes. Particularly, application of systems thinking provided useful analytical tool to explain how health system strengthening enables or constrains TB control. However, the participants were limited to frontline, district-level TB service providers. Given the emphasis on people-centred health system, perceptions and experiences of consumers TB service delivery systems would be an area of future research.

\section{Conclusion}

In conclusion, the findings of this study illustrate how health system factors drive control of TB in low resource settings. Given that governance influences both inputs and service delivery, governing TB control service delivery would entail effective oversight from NTP and local health system. Sustainable financing of TB would depend on stable and predictable domestic resource mobilisation through budgets and social health insurance. To attract and retain staff, human resource strategy must address training needs, lack of incentives to, and stigmatization of TB service providers. Furthermore, it is vital to strengthen TB drug and commodities' supply system and organization of service delivery. 


\section{Abbreviations}

ETBM:Electronic Tuberculosis Manager; FP:Focal person; HIV:Human immunodeficiency virus; LG:Local government; LGA:Local government area; LGTBS:Local government tuberculosis supervisor; LMICs:Lowand middle-income countries; NSP-TB:National strategic plan for tuberculosis control; NTP:National TB control programme; PHCC:Primary health care coordinator; TB:Tuberculosis; TB/HIV:Tuberculosis/ Human immunodeficiency virus; UHC:Universal health coverage; WHO:World Health Organisation.

\section{Declarations}

\section{Ethical approval and consent to participate}

Ethical clearance for this study was received from the health research ethics committee of Enugu State University Teaching Hospital, Enugu (ESUTHP/C-MAC/RA/034/VOL.11/30).

\section{Consent to publish}

The study did not include details, images or videos relating to individual participants, thus consent for publication were not required.

\section{Availability of data and material}

The dataset supporting the conclusions of this article is included within the article.

\section{Competing interests}

The author reports no conflict of interest.

\section{Funding}

None.

\section{Authors' contributions}

This article has a sole author. 


\section{Acknowledgements}

I am grateful to the local government supervisors and focal persons who participated in this study.

\section{References}

1. WHO. Global TB report 2018. Geneva: World Health Organisation; 2018.

2. WHO. The End TB strategy: global strategy and targets for tuberculosis prevention, care and control after 2015. . Geneva: World Health Organization; 2014.

3. Shigayeva A, Coker RJ. Communicable disease control programmes and health systems: an analytical approach to sustainability. Health Policy Plann. 2015;30:368-85.

4. Kohler S, Asadov DA, Bründer A, Healy S, Khamraev AK, Sergeeva N, et al. Health system support and health system strengthening: two key facilitators to the implementation of ambulatory tuberculosis treatment in Uzbekistan. Health Econ Rev. 2016;6:28.

5. Ogbuabor DC, Onwujekwe OE. Governance of tuberculosis control in Nigeria. Infect Dis Poverty. 2019;8:45.

6. Khan WM, Smith H, Qadeer E, Hassounah S. Knowledge and perceptions of national and provincial tuberculosis control programme managers in Pakistan about the WHO Stop TB strategy: a qualitative study. J Roy Soc Med Open. 2016;8(1):1-9.

7. Pai M, Daftary A, Satyanarayana S. TB control: challenges and opportunities for India. T Roy Soc Trop Med H. 2016;110(3):158-60.

8. Metzger P, Baloch NA, Kazi GN, Bile KM. Tuberculosis control in Pakistan: reviewing a decade of success and challenges. East Mediterr Health J. 2010;16:S47-S53.

9. Atun R, Weil DEC, Eang MT, Mwakyusa D. Health-system strengthening and tuberculosis control. Lancet. 2010;375:2169-78.

10. Otu AA. A review of the national tuberculosis and leprosy control programme (ntblcp) of Nigeria: challenges and prospects. Ann Trop Med Public Health. 2013;6(5):491-500.

11. Wynne A, Ritcher S, Banura L, Kipp W. Challenges in tuberculosis care in Western Uganda: Health care worker and patient perspectives. Int J Afr Nurs Sci. 2014;1:6-10.

12. Amo-Adjei J. Views of health service providers on obstacles to tuberculosis control in Ghana. Infect Dis Poverty. 2013;2:9.

13. Zou G, King R, Walley J, Yin J, Sun Q, Wei X. Barriers to hospital and tuberculosis programme collaboration in China: context matters. Glob Health Action. 2015;8(1):27067.

14. Churchyard GJ, Mametja LD, Hesseling AC, Reid A, Mvusi L, Babatunde S, et al. Tuberculosis control in South Africa: Successes, challenges and recommendations. S Afr Med J. 2014;104(3 (Suppl 1)):244-8. 
15. Zhou C, Long Q, Chen J, Xiang L, Li Q, Tang S, et al. The effect of NCMS on catastrophic health expenditure and impoverishment from tuberculosis care in China. Int J Equity Health. 2016;15:172.

16. de Vries G, Tsolova S, Anderson LF, Gebhard AC, Heldal E, Hollo V, et al. Health system factors influencing management of multidrug-resistant tuberculosis in four European Union countries learning from country experiences. BMC Public Health. 2017;17:334.

17. Li J, Shen X, Yeoh E, Chung P. Tuberculosis control programs and challenges in developed cities with intermediate disease burden: China experience. J Thorac Dis. 2017;9(5):E525-E8.

18. Ukwaja KN, Alobu I, Gidado M, Onazi O, Oshi DC. Economic support intervention improves tuberculosis treatment outcomes in rural Nigeria. Int J Tuberc Lung Dis. 2017;21(5):564-70.

19. Diwati LV, Mavundla TR, Mbengo F. facilitators for and barriers to the implementation of national tuberculosis management guidelines. Afr J Nurs Midwifery. 2018;19:3.

20. Rao KD, Ramani S, Hazarika I, George S. When do vertical programmes strengthen health systems? A comparative assessment of disease-specific interventions in India. Health Policy Plann. 2014;29:495-505.

21. Tobin-West Cl, Isodje A. Quality and rural-urban comparison of tuberculosis care in Rivers State, Nigeria. Pan Afr Med J. 2016;24:60.

22. Gebreegziabher SB, Yimer SA, Bjune GA. Qualitative Assessment of Challenges in Tuberculosis Control in West Gojjam Zone, Northwest Ethiopia: Health Workers' and Tuberculosis Control Program Coordinators' Perspectives. Tuberc Res Treat. 2016;2016:1-8.

23. Moosazadeh $M$, Amiresmaili $M$. Challenges in case finding of tuberculosis control program in Iran: $A$ qualitative study. Bangl J Med Sci. 2018;17(3):462-9.

24. Hartel LA, Yazbeck AS, Osewe PL. Responding to health system failure on tuberculosis in southern Africa. Health Syst Reform. 2018;4:2.

25. Krishnan I, Kumar A, Mini GK, Aravind LR. Evidence based interventions and implementation gaps in control of tuberculosis : a systematic review in low and middle-income countries with special focus on India. Indian J Tuberc. 2019;66(2):268-78.

26. Joshi B, Lestari T, Graham SM, Baral SC, Verma SC, Ghimire G, et al. The implementation of Xpert MTB/RIF assay for diagnosis of tuberculosis in Nepal: a mixed methods analysis. PLoS ONE. 2018;13(8):e0201731.

27. Rendell NL, Bekhbat S, Ganbaatar G, Dorjravdan M, Pai M, Dobler CC. Implementation of the Xpert MTB/RIF assay for tuberculosis in Mongolia: a qualitative exploration of barriers and enablers. PeerJ. 2017;5(7):e3567.

28. Linguissi LSG, Gwom LC, Nkenfou CN, Bates M, Petersen E, Zumla A, et al. Health systems in the Republic of Congo: challenges and opportunities for implementing tuberculosis and HIV collaborative service, research, and training activities. Int J Infect Dis. 2017;56:62-7.

29. Gebreegziabher SB, Bjune GA, Yimer SA. Patients' and health system's delays in the diagnosis and treatment of new pulmonary tuberculosis patients in West Gojjam Zone, Northwest Ethiopia: a crosssectional study. BMC Infect Dis. 2016;16:673.

Page 12/15 
30. Conseil A, Mounier-Jack S, Coker R. Integration of health systems and priority health interventions: a case study of the integration of HIV and TB control programmes into the general health system in Vietnam. . Health Policy Plann. 2010;25(suppl_1):i32-i6.

31. FMOH. The National Strategic Plan for Tuberculosis Control: Towards Universal Access to Prevention, Diagnosis and Treatment (2015-2020). Abuja, Nigeria: FMOH; 2014.

32. van Olmen J, Criel B, Bhojani U, Marchal B, van Belle S, Chenge MF, et al. Analysing health system dynamics-a framework. Stud Health Serv Organ Policy. 2012;2:1.

33. WHO. Everybody's business- strengthening health systems to improve health outcomes: WHO's framework for action. Geneva, Switzerland: World Health Organisation; 2007.

34. Fusch PI, Ness LR. Are We There Yet? Data Saturation in Qualitative Research The Qual Rep. 2015;20(9):1408-16.

35. Ukwaja KN, Alobu I, Igwenyi C, Hopewell PC. The high cost of free tuberculosis services: patient and household costs associated with tuberculosis care in Ebonyi State, Nigeria. PLoS ONE. 2013;8(8):e731134.

36. Ukwaja KN, Alobu I, Igwenyi C, Hopewell PC. Household catastrophic payments for tuberculosis care in Nigeria: incidence, determinants, and policy implications for universal health coverage. Infect Dis Poverty. 2013;2:21.

\section{Tables}

Table 1 Details of study participants

\begin{tabular}{|c|c|c|c|c|c|c|}
\hline \multirow[t]{2}{*}{ Participants } & \multirow[t]{2}{*}{ District } & \multirow[t]{2}{*}{$\begin{array}{l}\text { Number of } \\
\text { participants }\end{array}$} & \multicolumn{4}{|c|}{$\begin{array}{l}\text { Number of participants by level of care/health } \\
\text { facility }\end{array}$} \\
\hline & & & $\begin{array}{c}\text { Primary } \\
\text { health } \\
\text { centre }\end{array}$ & $\begin{array}{c}\text { Secondary } \\
\text { health } \\
\text { centre }\end{array}$ & $\begin{array}{c}\text { Tertiary } \\
\text { health } \\
\text { centre }\end{array}$ & $\begin{array}{c}\text { Faith- } \\
\text { based } \\
\text { hospital }\end{array}$ \\
\hline \multirow[t]{2}{*}{ LGTBS } & Urban & 4 & 4 & & & \\
\hline & Rural & 9 & 9 & & & \\
\hline \multirow{2}{*}{$\begin{array}{l}\text { Facility } \\
\text { focal } \\
\text { persons }\end{array}$} & Urban & 4 & 2 & 1 & 1 & 1 \\
\hline & Rural & 6 & 4 & 1 & & \\
\hline \multicolumn{2}{|c|}{ Total } & 23 & 19 & 2 & 1 & 1 \\
\hline
\end{tabular}


Table 2 Summary of key health systems enablers and constraints to implementation of

TB control in Enugu State, South-eastern Nigeria

\section{Key enablers Key constraints}

Leadership and governance

Stewardship from state-level NTP Weak bureaucratic accountability from local health system.

Programme management support Low government attention to TB control program

Regular performance review and

coordination

\section{Health financing}

External funding for TB control from donors

\section{Human resources}

Budgeted funds are not released to TB control program at the state level.

Absence of TB in local governments' budget.

TB supervisors' motorbikes are not replaced for several years.

Supportive supervision of facility

TB focal persons.

\section{Health technology}

Use of dedicated logistics agency for drug distribution.
Unwillingness of health workers to work in TB control programme

Frequent re-deployment of skilled TB service providers

High number of untrained TB service providers.

Health workers are owed several months of salaries

Logistics agency dumped drugs meant for entire local government in one location.

Drug kits does not meet needs of extrapulmonary TB patients and those weighing more than $70 \mathrm{~kg}$.

Shortage of human immunodeficiency virus (HIV) test kits.

\section{Health information system}

Availability of recording and reporting tools

Change in tools are not matched with training of service providers.

Adaptation of tools to strategies

in TB control.

Introduction of electronic

recording and reporting system

Service delivery

Availability of functional

Stigma by health workers 
microscopic centre

\section{Introduction of GeneXpert}

Engagement of community volunteers and patent medicine vendors

Reduction in duration of treatment from 8 to 6 months

\section{Concern for contracting TB}

Lack of incentives to attract health workers

Many TB treatment centres lack of TB laboratory

Poorly functioning GeneXpert.

Weak patient tracking system

Withdrawal of incentive for community volunteers and patent medicine vendors.

Limited number of TB/HIV collaborative sites.

\section{Figures}

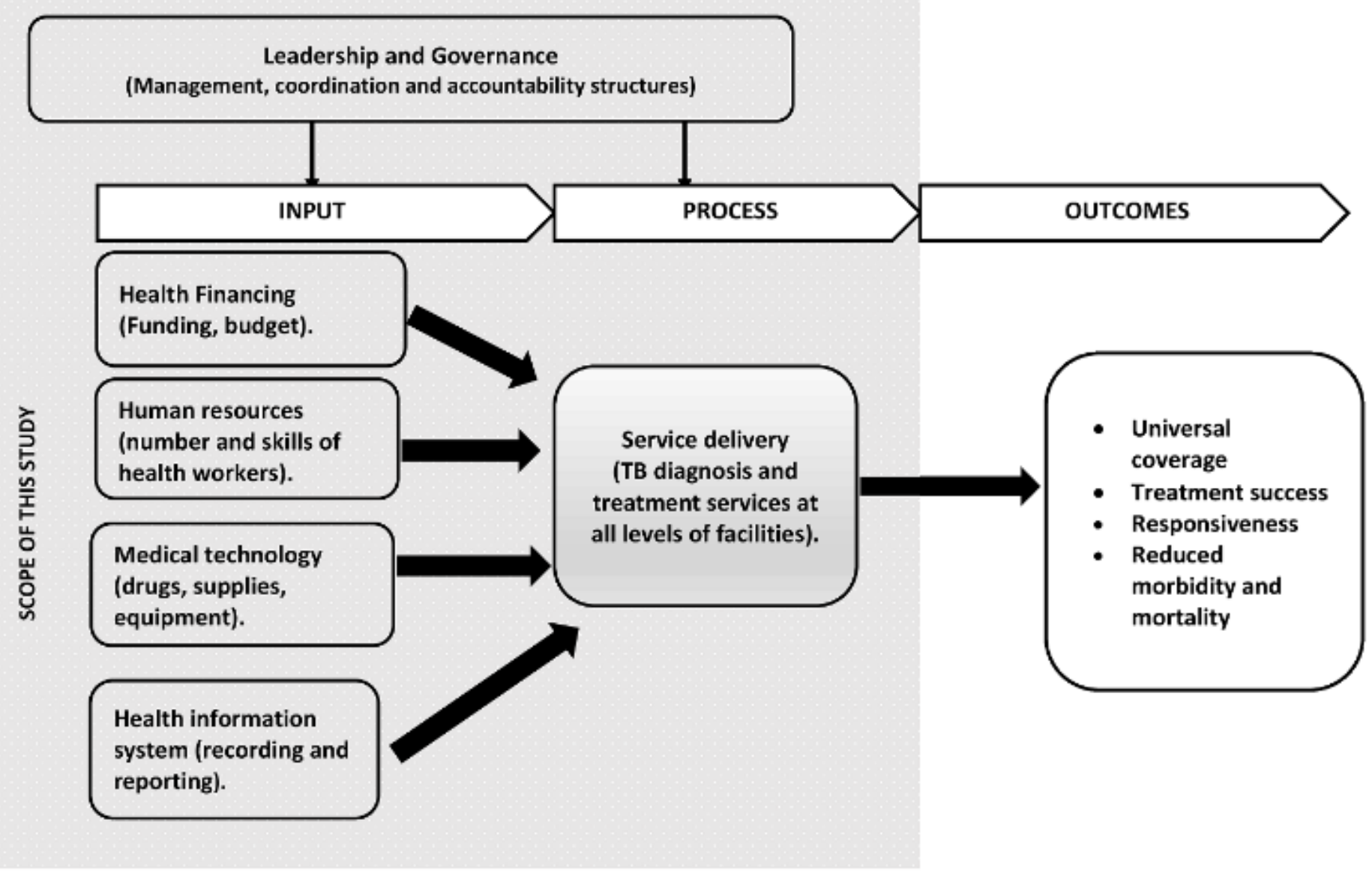

Figure 1 